\title{
Milton Hatoum na Internet: performance e epitexto digital
}

\author{
Ana Carolina da Conceição Figueiredo ${ }^{\mathrm{i}}$
}

\section{RESUMO}

Este artigo tem por objetivo discutir o posicionamento de Milton Hatoum na Internet, ressaltando a sua produção como cronista de revistas e jornais digitais e as conversas que ele trava com leitores e seguidores. Desse modo, pensaremos o parlatório da Internet como um espaço onde o escritor amazonense publica crônicas e faz postagens no perfil do Facebook. Nesse sentido, propomos a ideia da performance (ZUMTHOR, 2014) para explicar o desempenho de Milton Hatoum como escritor e intelectual, o qual faz comentários, postagens e críticas em crônicas da extinta Revista Eletrônica Terra Magazine e na rede social. Além disso, analisaremos os comentários abaixo das postagens do Facebook para refletirmos sobre as respostas imediatas entre o escritor e os seguidores, repensando a categoria epitexto proposta por Gerard Genette (2009).

Palavras-chave: Milton Hatoum; Internet; Performance; Crônicas; Epitexto digital.

\begin{abstract}
This article aims at discussing Milton Hatoum's projection on the Internet by highlighting his production writing chronicles for magazines and digital newspapers and his talks with the readers and followers. Thus, we will think of the Internet as the space where the Amazonian writer publishes chronicles and posts in his profile on Facebook. Considering that, we propose the idea of performance (ZUMTHOR, 2014) to explain Milton Hatoum's development as a writer and as an intellectual, who makes comments, posts and reviews in chronicles of the extinct digital magazine Terra Magazine and on social media. Furthermore, we will analyze the comments under the Facebook post so we can think about the immediate answer exchanges between the writer and the followers, rethinking the epitext category proposed by Gerard Genette (2009).
\end{abstract}

Keywords: Milton Hatoum; Internet; Performance; Chronicles; Digital Epitext.

\footnotetext{
${ }^{\text {i }}$ Mestra em Estudos Literários pelo Programa de Pós-Graduação em Letras e Linguística da Faculdade de Formação de Professores da Universidade do Rio de Janeiro (PPLIN-UERJ/FFP). Especialista em Estudos Literários pelo Departamento de Letras da FFP/UERJ.

ORCID: https://orcid.org/0000-0001-9151-0863 | karolfigueiredo@hotmail.com
} 


\section{INTRODUÇÃO}

Na era da mediatização total da experiência, a literatura pode ser considerada como forma liminar de representação social, internamente marcada pela diferença cultural e por novas possibilidades de sentido e significação.

Wander Miranda (2010, p. 121-129)

A globalização impulsionou a circulação de obras literárias em canais de comunicação, como a Internet, comparativamente ao que se via antes do apogeu da tecnologia, em que o texto literário circulava em rodapé de jornais, nas revistas literárias e nos livros impressos. A circulação virtual das obras literárias acaba rompendo com alguns limites e limitações das publicações daqueles espaços, que não permitiam um trânsito maior dos leitores e sua interação com o autor e com o próprio texto. Com essa ruptura, romances, contos, crônicas e poemas de escritores diversificados encontram-se disponíveis no formato $e$-book, são publicados em blogs, sites e redes sociais, permitindo, assim, uma ampla movimentação no campo literário.

Diante desse cenário, o livro impresso passou a concorrer com o e-book e os blogs, que servem adicionalmente como instrumento de divulgação para novos escritores. Para Beatriz Resende (2008, p. 17), “a verdade é que os jovens escritores não esperam mais a consagração pela 'academia' ou pelo mercado. Publicam como possível, inclusive usando as oportunidades oferecidas pela Internet. E mais, formam listas de discussão, comentam uns com os outros [...]”. Essa literatura publicada em blogs não é exclusividade deste suporte, pois pode vir também em livros. Esse tipo de publicação em blogs atinge o objetivo do escritor de levar a sua produção literária a seu público com mais rapidez, sem ficar dependente das editoras para divulgar a obra.

Milton Hatoum é um escritor contemporâneo que, além de lançar romances em livros impressos, publicou crônicas na Revista Eletrônica Terra Magazine por um período de quatro anos e publica, atualmente, em jornais digitais, como O Estado de São Paulo. Em seu perfil no Facebook, Hatoum esbraveja contra as atitudes, falas e decisões do governo bolsonarista. Nesse aspecto, recentemente, após o MEC apresentar o "Future$\mathrm{se}^{1}$ ", plano que propõe alterações no financiamento das universidades federais, Hatoum postou em sua página no Facebook sua aversão: “O diversionismo é uma manobra sórdida para confundir e enganar as pessoas. A raposa astuta lança uma ideia ou proposta 
execrável, enquanto a privatização do ensino público é um dos objetivos da política insidiosa do atual governo" (HATOUM, 2019b).

A partir das discussões supracitadas, este artigo tem por objetivo, em primeiro lugar, refletir sobre o posicionamento de Milton Hatoum na Internet, quando ele se divide entre as publicações nos jornais digitais e no Facebook. Nesse sentido, pensaremos a performance (ZUMTHOR, 2014) do escritor amazonense na Web e, também, o seu engajamento diante dos problemas sociais, estimulando o pensamento crítico do leitor frente às lutas para um Brasil democrático.

Em segundo lugar, analisaremos as conversas travadas entre Hatoum e alguns de seus seguidores, após as postagens do escritor em seu perfil do Facebook, para mostrar a rapidez das respostas e os novos formatos de epitextos (GENETTE, 2009) digitais.

\section{A PERFORMANCE DE MiLTON HATOUM NO PARLATÓRIO DA INTERNET}

Na era do mercado, a condição paratópica (MAINGUENEAU, 2001) reveste-se de peculiaridades, pois o sistema paratópico é desenhado por um contexto que vai dos aspectos sociais ao campo literário, espaço onde o escritor está submetido a regras. Uma delas é a impossibilidade de o escritor conseguir um lugar verdadeiramente seu (mas se até a própria inserção desse campo literário na sociedade tem um viés problemático, o respingo no escritor só poderia ser perigoso mesmo). Isso porque "a pertinência ao campo literário não é, portanto, a ausência de qualquer lugar, mas antes uma negociação difícil entre o lugar e o não lugar, uma localização parasitária, que vive da própria impossibilidade de se estabilizar" (MAINGUENEAU, 2001, p. 28).

Nesse lugar de instabilidade, chamado de paratopia por Dominique Maingueneau, o escritor precisa decidir se escolhe "aderir e pertencer, recusar e resistir, posicionandose diante de desafios como a atração pelo sucesso comercial em detrimento do 'autêntico' trabalho criador" (HELENA \& OLIVEIRA, 2016, p. 221-222). Desse modo, o escritor encontra-se diante de uma questão: a liberdade de criação de sua obra ou o sucesso de vendas; ambos, porém, são desejáveis e importantes para o sujeito escritor-intelectual, habitante desse entre-lugar problemático. Logo, “como pode, então, o artista se colocar 
em relação a um suposto ideal artístico, sem desconsiderar as prerrogativas do mercado, com suas leis e regras?" (HELENA \& OLIVEIRA, 2016, p. 222).

A pergunta colocada por Lúcia Helena e Paulo Oliveira (2016) nos direciona para pensarmos a Internet como um meio de publicação e divulgação da obra, que beneficia o escritor no mercado, devido à divulgação rápida e o diálogo com o público, afirmando o papel do escritor no campo literário e propagando a sua posição no campo intelectual. Dessa forma, a circulação do escritor e de suas obras na Internet acaba sendo uma das prerrogativas do mercado, tendo em vista que há um público na Web consumidor de livros nos mais variados formatos. Por isso, alguns escritores, de certo modo, são obrigados a ceder às regras desse meio e fazem da Internet o seu parlatório.

Entendemos o parlatório como um "recinto separado por grades, no qual é permitido às pessoas recolhidas em conventos ou mantidas em prisões conversar com as de fora que as visitam” (E-DICIONÁRIO HOUAISS, 2017). Todavia, o parlatório também pode ser o lugar da "conversa informal, agradável, sem assunto específico"; ou uma "conversa barulhenta", um "falatório"; ou ainda, algo que se pratica "em prédios públicos, espécie de balcão onde as autoridades apresentam-se para discursar”.

No parlatório da Internet, Milton Hatoum é levado a se posicionar criticamente em relação às mazelas enraizadas na sociedade. Ele desconstrói a imagem do escritor em silêncio, passando a utilizar sua voz para se posicionar em favor dos direitos iguais, da justiça, do respeito à diferença, da dignidade, do conhecimento e da diversidade de culturas e identidades. Desse modo, Hatoum "dá a cara a tapa" mediante a liberdade no campo da Internet - no seu perfil do Facebook é possível ver o seu posicionamento cidadão e a sua visão crítica sobre a política e outros temas atuais. O escritor amazonense atua, a nosso ver, na qualidade de militante, falando por vezes compulsivamente e expondo com ênfase suas críticas ao status quo e à problemática realidade brasileira (AUTOR, 2019).

Os novos suportes de veiculação de obras literárias põem em destaque a performance do escritor. De acordo com Paul Zumthor (2014, p. 51), performance "designa um ato de comunicação como tal; refere-se a um momento tomado como presente. A palavra significa a presença concreta de participantes implicados nesse ato de maneira imediata [...] Ela atualiza virtualidades [...] sentidas com maior ou menor clareza”. Dito isso, queremos destacar os movimentos performáticos de Milton Hatoum, 
escritor e intelectual que transita com liberdade na Internet, já que habitualmente posta as suas crônicas no perfil do Facebook, concede entrevistas virtuais e trava diálogos via inbox com o público. A liberdade com que Hatoum circula as crônicas pela Internet permite que os leitores façam comentários em tempo real sobre os seus textos. Nesse sentido, discutiremos a performance de Milton Hatoum na Revista Eletrônica, suporte eletrônico onde o escritor publicou crônicas de 2006 até 2010, ressaltando a variedade temática e o hibridismo dos gêneros. Abordaremos as crônicas "Amazônia: um pouco antes do fim" (HATOUM, 2008a) e "Ainda Amazônia" (HATOUM, 2008b) - a primeira gerou uma discussão com um leitor, o que fez Hatoum escrever a segunda.

Milton Hatoum publicou, na Revista Eletrônica Terra Magazine, um total de 56 crônicas com temas variados - educação, religião, literatura, política, memória, entrevista, infância etc. Além disso, essas crônicas trazem um regime de textos híbridos - em que Hatoum recorre a formas de poemas, contos, cartas, artigos e ensaios. Essas combinações textuais resultam em marcas de estilos e configuram uma singular poética de autor, e por isso é conveniente para essa discussão propor a ideia de que a crônica é sempre "crônica de", no caso, "crônica de" Milton Hatoum. Portanto, a poética de Hatoum consiste em uma "produção literária de caráter político-militante e estruturante construída sob a crônica, um gênero contestado, mas que possui um capital que não pode ser negado de todo, ao mesmo tempo, sem que a ele nos submetamos" (AUTOR, 2019, p. 34).

As temáticas apresentadas nessas crônicas mostram-nos um Milton Hatoum como intelectual engajado em causas sociais e nas questões políticas e culturais e por isso também se verifica em seus textos uma vontade de elaborar "uma linguagem que fala de perto", que "pega o miúdo e mostra nele uma grandeza, uma beleza ou uma singularidade insuspeitada", nas palavras de Antonio Candido (1992, p. 14). Hatoum problematiza o senso crítico da comunidade leitora quando demanda a participação do leitor para a discussão travada no texto. Nesse sentido, sua crônica nos "ensina a conviver intimamente com a palavra, fazendo com que ela não se dissolva de todo ou depressa demais no contexto, mas ganhe relevo, permitindo que o leitor a sinta na força dos seus valores" (CANDIDO, 1992, p. 15).

O perfil de escritor intelectual de Milton Hatoum apresenta-se em "Amazônia: um pouco antes do fim" de modo múltiplo, seja ao evocar a participação social dos sujeitos 
oriundos da Amazônia, seja por sua crítica à impunidade dos políticos. Com base no fragmento "A Amazônia é um infinito que deve ser dosado", do livro À margem da história (1909), de Euclides da Cunha (1866-1909), Hatoum considera a importância de estudar a Amazônia em seus detalhes, tendo em vista que "cada rio tem uma história com particularidades geográficas, sociais, culturais, simbólicas. Cada trecho da floresta possui uma riqueza ambiental e humana que deve ser estudada, analisada" (HATOUM, 2008a).

A escrita de Hatoum na crônica supracitada desenvolve-se como uma composição fragmentada, em quatro partes, pois é notório um movimento de expressão não apenas no modo como a discussão vai sendo construída, mas também pelas informações que fundamentam as justificativas e os pressupostos apontados. Nesse sentido, a crônica é composta de um fazer crítico e literário, comum nas obras literárias, até pela liberdade do autor ao se expressar nos veículos de comunicação, sites, blogs, redes sociais etc.

As considerações do autor de Dois irmãos (2000) sobre o desmatamento de florestas pertencentes aos territórios da Amazônia produziram opiniões variadas e contraditórias, que resultaram em comentários e em assunto para outra crônica, intitulada "Ainda a Amazônia" (HATOUM, 2008b). Nela, o autor tece diálogo com um leitor, que o critica por generalizar o assunto em questão.

Desse modo, pensa-se que há uma autonomia do escritor ao dedicar a crônica de 23 de junho de 2008 uma resposta ao leitor. Em outras palavras, uma resposta que consiste em uma "conversa barulhenta" em que se percebe a necessidade do autor de responder a esse leitor, mostrando com brevidade linguística que as grades que separam autor e público apresentam um enfraquecimento produzido pelas mudanças do contexto mercadológico cultural contemporâneo:

\footnotetext{
Vários leitores me enviaram mensagens com comentários sobre a crônica Amazônia: um pouco antes do fim. Um senhor simpático - que há trinta anos mora em Rondônia - argumentou que o plantio de soja fertiliza o solo duro da região. O solo nu, desmatado; o solo que acolhe o novo milagre redentor, o maná do novo eldorado: a soja. Esse leitor criticou a generalização do meu texto, dando a entender que eu desconheço a região amazônica (HATOUM, 2008b).
}

A performance de Milton Hatoum no parlatório, separado do público por grades (ou, em outros termos, sua condição de intelectual), pode ser problematizada e questionada, quando este se apresenta como intelectual engajado, tendo em vista que 
discute um problema social, faz uma escrita de denúncia com vistas a provocar a sociedade. Nesse sentido, entendemos que a performance de Hatoum na Internet "é um saber que implica e comanda uma presença e uma conduta" (ZUMTHOR, 2014, p. 34). Pode se concluir que o modo como escritor e público leitor dialogam nas crônicas "Amazônia: um pouco antes do fim" (HATOUM, 2008a) e "Ainda a Amazônia" (HATOUM, 2008b) e seus efeitos nas redes sociais indicam que o distanciamento entre escritor e comunidade leitora começa a ruir nessa fase atual do mercado.

\section{DO PARATEXTO DO LIVRO AO DA INTERNET: UMA LEITURA DO EPITEXTO DIGITAL DO FACEBOOK}

Os meios digitais - redes sociais, colunas de jornais e revistas, chats e blogs - dão liberdade para que qualquer pessoa possa opinar e expor pensamentos, ideias e argumentos sobre um determinado assunto. Nesse sentido, concordaremos que as opiniões têm relação com os gostos, os desgostos, as experiências e as subjetividades: "Todos nós dialogamos com o mundo do senso comum e da subjetividade. Argumentos objetivos e verificáveis existem, mas escasseiam nas discussões diárias" (KARNAL, 2019). Nesse circuito desenfreado pela opinião, cada um quer dizer o que pensa, resultando em debates constantes nos meios digitais. Muitas vezes, a TV e o rádio, também, são cenários de discussões que terminam em ofensas e em violências. Para Leandro Karnal (2019), esses motivos levaram "Umberto Eco a emitir sua antipática (e verdadeira?) sentença de que a Internet (e principalmente as redes sociais) deu a certeza ao idiota da aldeia de que ele não apenas tem voz; concedeu-lhe a certeza de que tudo sabe; de que sua opinião é a melhor, a mais correta". Apesar de todo embate, ainda é preferível ouvir os idiotas a ter de conviver com a mordaça da ditadura (KARNAL, 2019).

Com isso, ocorre, hodiernamente, no campo virtual, uma corrida apressada pela opinião, que nomearemos, a partir das considerações de Leandro Karnal em texto publicado em sua coluna do Estadão em março de 2019, de "O barulho democrático". Nesse texto, Karnal afirma a existência de uma tripla força geradora de opiniões, sendo assim, na primeira linha, está o estado democrático de direito, que na Constituição é o espaço onde todo indivíduo deve ter preservada sua liberdade de expressão. Sobre a segunda e terceira forças, o historiador brasileiro explica: 


\begin{abstract}
A segunda força é o crescimento do sujeito como definidor de uma realidade que deve ser respeitada por causa da vontade. "Por que essa profissão? Por que fez tal escolha de casamento?" A resposta que encerra tudo é "porque eu gosto". O declínio do dever ou da norma e a ascensão do desejo como instaurador de validade são recentes e mereceriam muita análise. A terceira e última força se chama rede social. Não apenas eu tenho o direito, eu também penso assim e, por fim, posso publicar para milhões a minha infinita subjetividade. Estamos no apogeu da doxa como o grande critério da comunicação (KARNAL, 2019).
\end{abstract}

Assim sendo, compreendemos que o parlatório da Internet tem a rede social como terceira e última força, fazendo com que as opiniões pessoais ganhem destaques e sejam motivos de contendas e polêmicas. Nessa perspectiva, o escritor no parlatório, que para nossa discussão é representado por Milton Hatoum, ao publicar suas crônicas e defender suas opiniões em sua página pessoal do Facebook, atua no campo intelectual de forma a contribuir para o barulho democrático, que conta com a participação de seus inúmeros seguidores. Dessa forma, com base na ideia de barulho democrático proposta por Karnal (2019), pensaremos o espaço situado abaixo da coluna do jornal/revista ou da postagem do Facebook, onde os leitores esgrimam o que pensam.

Gerard Genette (2009, p. 9), no livro Paratextos editoriais, entende por paratexto "aquilo por meio de que um texto se torna livro e se propõe como tal a seus leitores, e de maneira mais geral ao público.” Desse modo, Genette dividiu o paratexto em 1) peritexto - está situado em torno do texto como o nome do autor, o título, os intertítulos, ilustrações, epígrafe, capa, orelha, quarta-capa, etc; E o 2) epitexto - encontra-se "ainda em torno do texto, mas uma distância mais respeitosa (ou mais prudente), todas as mensagens que se situam, pelo menos na origem, na parte externa do livro: em geral num suporte midiático (conversas, entrevistas), ou sob a forma de uma comunicação privada (correspondências, diários íntimos e outros)." (GENETTE, 2009, p. 12). Convém afirmar que a paratextualidade forma os cinco tipos de transtextualidade, ou seja, "tudo que o coloca em relação, manifesta ou secreta, com outros textos" (GENETTE, 2010, p.13).

Embora a definição de paratexto proposto por Genette faça referência à obra literária, entendemos que não cabe mais limitar essa categoria somente ao livro, uma vez que as atuais mídias digitais - por exemplo, o Facebook - possuem um espaço localizado abaixo das publicações e das postagens, que pode, a nosso ver, ser classificado como epitexto digital. Dessa forma, o termo digital é empregado, tendo em vista que esses 
epitextos encontram-se na web. Nesse formato de epitexto, a agilidade da interação é algo próprio e inseparável, que, com o passar dos anos, consolida-se. Apesar de, na obra supracitada, Genette não trazer o epitexto da web como tema de discussão ao longo dos capítulos, ele compreende que:

[...] os caminhos e meios dos paratextos não cessam de modificar-se conforme as épocas, as culturas, os gêneros, os autores, as obras, as edições de uma mesma obra, com diferenças de pressão às vezes consideráveis: é uma evidência reconhecida que nossa época "midiática" multiplica em torno dos textos um tipo de discurso desconhecido no mundo clássico, e a fortiori na Antiguidade e na Idade Média, época em que os textos circulavam muitas vezes em estado quase bruto, sob a forma de manuscritos desprovidos de qualquer fórmula de apresentação. (GENETTE, 2009, p. 11)

O modo como o epitexto digital vem organizado já prevê a interação do leitor com o texto, que ocorre através da modalidade da escrita, da imagem, do vídeo e da linguagem dos emoticons, dos stickers e dos emojis. Essa variedade de ferramentas permite que o leitor tenha mais opções para construir os comentários e respostas, os quais ganharão forma e sentido ao entrar em contato com o texto publicado acima dos comentários. Dessa forma, para Genette $(2009$, p. 9), “o paratexto é aquilo por meio de que um texto se torna livro e se propõe como tal a seus leitores, e de maneira mais geral ao público", estabelecendo uma continuidade. Embora o conceito paratextual esteja relacionado à literatura e ao livro, o modo como o paratexto configura-se vem passando por inovações ao longo das épocas. Tais transformações ganham força e destaque facilitando, assim, a divulgação e propagação do discurso em grande escala. Portanto, entendemos, conforme Edson Fernando Dalmonte (2009), que:

\footnotetext{
A partir da premissa de que não existe texto sem paratexto, tal realidade abre uma série de questões quando se pensa nas potencialidades abertas pelas novas mídias. Merece relevo, a partir da nova fluidez textual dos ambientes digitais, a forma como os textos podem se desdobrar em blocos que se espalham pela web, de autorias diversas, mas conectados ao assunto em questão. Entre opiniões favoráveis e contrárias, outras narrativas são estabelecidas a partir do texto original, conservando, contudo, a ligação com o protótipo, passando a compor um só texto, multilinear e multivocal (DALMONTE, 2009, p. 116).
}

Pensaremos a interação do leitor no epitexto digital, analisando dados retirados da página pessoal do Facebook de Milton Hatoum, a fim de refletir sobre os temas abordados e o formato desses textos desdobrados em blocos. No dia 25 de julho de 2019, Milton 
Hatoum compartilhou uma reportagem do site da Folha de São Paulo, que tem como título "Investir na educação e exercer autoridade em sala de aula, diz Bolsonaro". A reportagem de Fabiano Maisonnave, datada também de 25 de julho de 2019, relata e comenta a visita do presidente às escolas da Polícia Militar em Manaus. Aborrecido com a fala de Bolsonaro - em que se lê: "Investir na educação é dar meios para que o professor possa exercer a sua autoridade em sala de aula e, dessa forma, poder fazer com que os alunos realmente aprendam" -, Hatoum compartilha a notícia e, em texto curto de sua autoria, escreve em crítica à fala do presidente:

\footnotetext{
Há visão mais rasa sobre Educação? Esse retrocesso será trágico para uma geração de jovens. Aliás, trágico para o país. Cortaram as bolsas da Capes, e este é apenas um dos tantos absurdos. No fundo, é a privatização do ensino público que está no horizonte (nefasto) dessa gente. Que maneira destruidora de ver o mundo e a sociedade! (HATOUM, 2019).
}

A partir dessa postagem de Hatoum, os seguidores (leitores também de suas obras literárias) expressam opiniões e, em tempo real, verificam e comentam a publicação de outros seguidores. Com isso, instaura-se no epitexto um "barulho democrático", pois cada um escreve o que compreende como mais coerente e correto. Por vezes, é possível encontrar pessoas discordando sobre o comentário uns dos outros ou tecendo críticas à posição política defendida por alguns, tendo em vista que, para espanto nosso, há quem defenda as colocações do presidente. Além disso, notamos que certos seguidores usam argumentos de autoridades para embasar e construir o seu pensamento. Vejamos: 
Figura 1: Exemplos de comentários de seguidores de Milton Hatoum publicados no Facebook de Milton Hatoum no dia 25 de julho de 2019

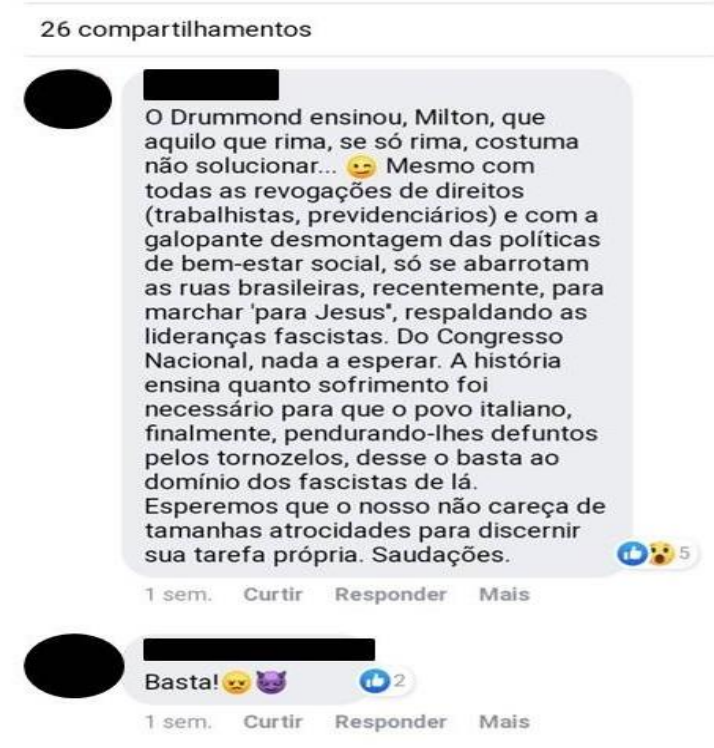

Figura 2: Exemplos de dois comentários da mesma seguidora publicados no Facebook de Milton Hatoum também no dia 25 de julho de 2019.

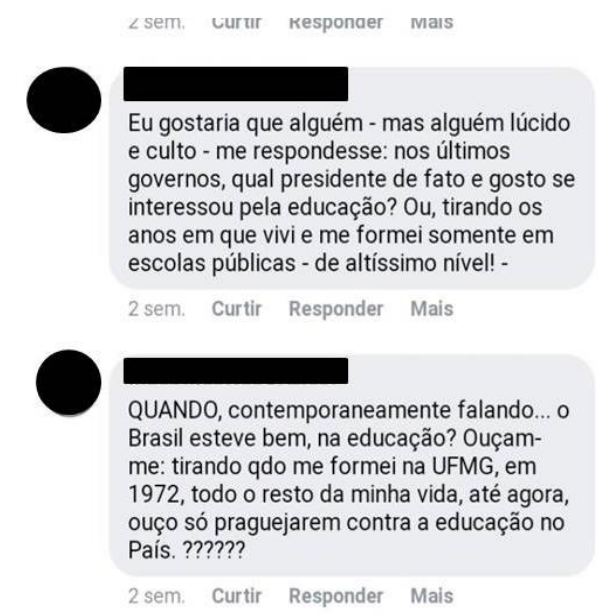

$\mathrm{Na}$ primeira figura, podemos observar ferramentas diferentes utilizadas pelos interlocutores para construírem as suas respostas. Dito isso, encontramos emojis que marcam a preferência do comentarista e também a dos outros seguidores simpatizantes, pois as escolhas deixam claro o que eles pensam e expressam emoção. Além disso, notase uma coerência no emprego dos emojis com o texto grafado, por exemplo, no último epitexto digital, a mistura da frase "Basta!" aos emojis enfatiza a irritação e a fúria, 
podendo indicar, numa possível leitura, o desejo do comunicador de intervir e de protestar contra o desgoverno atual.

De acordo com as nossas leituras, entendemos que o autor do comentário inicial da figura 1, quando menciona com base em Carlos Drummond de Andrade, "[...] aquilo que rima, se só rima, costuma não solucionar [...]", está fazendo referência às opiniões convergentes de uma grande parcela dos brasileiros que discorda das decisões e das afirmações do presidente. Nesse sentido, ele parece afirmar que as pessoas insatisfeitas devem se unir, a fim de abarrotar as ruas das cidades do país em protestos, isto é, irem à luta, mostrando nas ruas a força do povo brasileiro. Para fundamentar a sua fala, esse seguidor de Hatoum aborda a história do povo italiano que "ensina quanto sofrimento foi necessário para que [...], finalmente, pendurando-lhes defuntos pelos tornozelos, desse o basta ao domínio dos fascistas de lá." Tais colocações supõem que ele tem o intuito de chamar a população contrária ao desgoverno para irem às ruas protestarem.

$\mathrm{Na}$ segunda figura, os comentários da interlocutora fazem-nos pensar nela, supostamente, como adepta das ideias bolsonaristas no que diz respeito à educação. Em primeiro lugar, na indagação presente no comentário número 1: "Eu gostaria que alguém - mas alguém lúcido e culto - me respondesse: nos últimos governos, qual presidente de fato e gosto se interessou pela educação?”. Ela não só enfatiza os problemas educacionais do Brasil, mas também diz que os maus investimentos já são, estatisticamente, dados advindos das últimas administrações governamentais. Todavia, de acordo com a seguidora, os anos em que ela se formou as escolas públicas eram "de altíssimo nível!", semelhantemente ao período em que ela estudou na UFMG, em 1972. O ponto polêmico da discussão é que ela considera o ano de 1972, período do Regime Militar, como a época em que "o Brasil esteve bem na educação", por isso, supomos que a interlocutora é simpatizante da proposta do presidente mencionada na reportagem de Fabiano Maisonnave supracitada. O uso dos pontos de interrogação, ao final do comentário, realça a ênfase na pergunta levantada.

As novas tecnologias virtuais possibilitam uma fluidez textual, pois acontece um compartilhamento em outros veículos de comunicação, onde um determinado texto, a partir da interação dos internautas, desdobra-se em novos blocos sem perder a relação com o texto central da discussão. Reiterando Dalmonte (2009, p. 116): "Entre opiniões favoráveis e contrárias, outras narrativas são estabelecidas a partir do texto original, 
conservando, contudo, a ligação com o protótipo, passando a compor um só texto, multilinear e multivocal." Nesse caso, a reportagem da Folha de São Paulo produzida por Fabiano Maisonnave é o texto original formado por um hipertexto, o qual abriga uma multiplicidade de outras informações, porque é "constituído de nós (os elementos de informação, parágrafos, páginas, imagens, sequências musicais etc.) e de ligações entre nós (referências, notas, indicadores, 'botões' que efetuam a passagem de um nó a outro)" (LÉVY, 1996). Ademais, depois de compartilhado nas redes sociais, dá margem para o surgimento de várias vozes discursivas contrárias ou favoráveis entre si presentes nos epitextos digitais do Facebook. Com essas discussões, pensamos que a participação de Milton Hatoum nessa rede social possibilita a sua participação numa nova comunidade: a comunidade discursiva da Web.

\section{CONSIDERAÇÕES FINAIS}

A publicação de obras literárias na Internet é cada vez maior, pois os blogs, os sites e as revistas eletrônicas veiculam variados gêneros, até mesmo textos de crítica literária, resenhas, ensaios, dentre outros. Um dado valioso diz respeito ao fato de os próprios escritores assumirem a função de críticos das obras de seus pares. Com isso, as editoras, que ainda editam livros, acabam descobrindo novos autores, novas obras literárias e novas tendências.

Milton Hatoum integra uma tribo, grupo de autores, homens intelectuais, que produzem narrativas de militâncias para retratarem as mazelas do tempo atual e, portanto, são capazes "de perceber e apreender o seu tempo" (AGAMBEN, 2010, p. 58-59). Outro fator que os une é a tribuna da Internet, espaço onde eles travam "uma conversa barulhenta", um falatório que os situa no mercado e os coloca numa posição instável, "mesmo quando entre eles falta um diálogo mais evidente" (HELENA \& OLIVEIRA, 2016, p. 222).

Tal ideia de tribo é constituída dentro do campo literário e pode ser pensada como: grupo, escola, confraria, círculo etc, mas não estão definidas segundo os mesmos pressupostos sociais valorativos canônicos. Os sujeitos, membros das tribos literárias, são oriundos de famílias, embora a tribo não tenha relação com a concepção de família. Além do mais, o pertencimento a uma mesma tribo não garante que os escritores coabitem 
lugares semelhantes, pois até mesmo as trocas de correspondências, influências de certos autores, as atitudes de militâncias em defesa de causas sociais convergentes, por exemplo, podem resultar numa tribo.

A performance de Milton Hatoum na Internet confronta, dessa forma, a imagem do escritor solitário quando se reúnem numa tribo. Nessa perspectiva, podemos desconstruir a visão da singularidade do escritor, defendida pela visão romântica. Em razão disso, o próprio conceito-chave de tribo nos faz crer, a partir da escrita e da posição no campo intelectual, na imagem de um escritor que, não apenas mantém uma filiação a escritores antepassados, mas também busca conquistar um espaço no campo literário, quando "insere-se em comunidades discursivas, afetivas, estéticas" (HELENA \& OLIVEIRA, 2016, p. 231) e midiáticas, como acontece na Web.

No diálogo presente no epitexto digital do Facebook, encontramos um "bate boca" democrático nas crônicas "Amazônia: um pouco antes do fim" e "Ainda a Amazônia", ambas publicadas em julho de 2008, porque existe uma conversa entre o escritor e o leitor, apesar de não ser em tempo real, visto que as crônicas eram publicadas quinzenalmente. Vale destacar que, durante a pesquisa das crônicas na página eletrônica da Terra Magazine, nós não conseguimos ter acesso à página e ao comentário do leitor, porque o site da Revista não está disponível. Logo, só tivemos acesso às considerações desse leitor através da leitura da crônica "Ainda Amazônia".

As reflexões surgidas a partir das leituras dessas crônicas não só nos permitiram compreender a crônica como textos de fruição, mas também nos possibilitaram questionar a ideia do gênero menor. Sabemos que tal nomeação refere-se ao tempo de escrita da crônica, mais breve do que o tempo da produção de um romance, por exemplo. Entretanto, a qualidade de gênero menor diz respeito também a seu caráter extraliterário, já que se encontra à margem ou em outras dimensões, diversas do processo de elaboração, difusão e consumo dos gêneros considerados canônicos ou prestigiosos. Compreendemos que as leituras das crônicas da Terra Magazine descontroem essas afirmações e mostram que o enquadramento dessa produção na qualidade de gênero menor não é mais pertinente, uma vez que, como texto que age de forma mais imediata sobre o horizonte de expectativa do leitor, ganha constantes reconfigurações, especialmente na contemporaneidade, com seus meios mais velozes, diretos e democráticos, podendo concluir que a espécie literária 
crônica adquiriu ao longo de seu percurso histórico "uma identidade literária coletivamente reconhecida" (JOUVE, 2012, p. 32) para desespero dos críticos opositores.

Os pensamentos referentes ao posicionamento do escritor no parlatório levaramnos a indagar as reconfigurações da categoria autor no cenário contemporâneo, problematizando suas ressignificações a partir da noção de participação, tanto física, quanto digital, em espaços públicos. Isso porque observamos que há um grande número de cronistas que não se limitam ao trabalho "de gabinete", colocando-se em constante interação com o público e participando do campo intelectual (Cf. MAINGUENEAU, 2010). Essa participação coloca em questão alguns princípios das teorias da literatura e provoca nossa reflexão sobre a emergência de um novo perfil do escritor, um escritor no parlatório.

\section{Referências}

AGAMBEN, Giorgio. O que é o contemporâneo? e outros ensaios. 2. reimp. Chapecó, SC: Argos, 2010.

CANDIDO, Antonio. A vida ao rés-do-chão. In: . A crônica: o gênero, sua fixação e suas transformações no Brasil. Campinas, SP: Editora da UNICAMP; Rio de Janeiro: Fundação Casa de Rui Barbosa, 1992, p. 13-22.

DALMONTE, Edson Fernando. A esfera paratextual: o lugar do leitor-participante no webjornalismo. Revista Galáxia, São Paulo, n. 18, p.113-124, dez. 2009.

E-DICIONÁRIO HOUAISS. Disponível em: https://houaiss.uol.com.br/pub/apps/www/v3-3/html/index.php\#1. Acesso em 22 de outubro de 2017.

FIGUEIREDO, Ana Carolina da Conceição. Milton Hatoum no parlatório: entre crônicas e paratextos digitais. Dissertação. (Mestre em Estudos Literários). Faculdade de Formação de Professores da Universidade do Estado do Rio de Janeiro, São Gonçalo, Rio de Janeiro, 2019.

GENETTE, Gérard. Paratextos editoriais. São Paulo: Ateliê, 2009.

Cinco tipos de transtextualidades, dentre os quais a hipertextualidade. In: Palimpsestos: a literatura de segunda mão. Belo Horizonte: Edições Viva Voz, 2010, p. 13-21.

HATOUM, Milton. Amazônia: um pouco antes do fim. (9 de jun. 2008a). http//terramagazine.com.br. Acesso em: 27 de novembro de 2008. 
Ainda Amazônia. (23 de jun. 2008b). http//terramagazine.com.br. Acesso em: 27 de novembro de 2008.

Milton Hatoum. Perfil do Facebook. São Paulo, 18 de jul. 2019b. Disponível em: https://m.facebook.com/profile.php?id=100006340536397\&ref=content_filter. Acesso em: 10 de setembro de 2019.

Milton Hatoum. Perfil do Facebook. São Paulo, 25 de jul. 2019c. Disponível em: https://m.facebook.com/profile.php?id=100006340536397\&ref=content_filter. Acesso em: 10 de setembro de 2019.

HELENA, Lúcia; OLIVEIRA, Paulo César de. Cenas da textualização: mobilidade e clausura. In: _. Uma literatura inquieta: memória, ficção, mercado e ética. Rio de Janeiro: Caetés, 2016, p. 221-243

JOUVE, Vincent. Por que estudar literatura? São Paulo: Parábola, 2012.

KARNAL, Leandro. O barulho democrático. O Estado de São Paulo, São Paulo, 03 de março de 2019. Disponível em: https://cultura.estadao.com.br/noticias/geral,o-barulhodemocratico,70002740826. Acesso em: 10 de setembro de 2019.

LÉVY, Pierre. O que é o virtual? São Paulo: Ed. 34, 1996.

MIRANDA, Wander Melo. Ficção virtual. In: . Nações literárias. Cotia, SP: Ateliê Editorial, 2010, p. 121-129.

MAINGUEANEAU, Dominique. O contexto da obra literária: enunciação, escritor, sociedade. 2. ed. São Paulo: Martins Fontes, 2001.

MAISONAVE, Fabiano. Investir na educação é exercer autoridade em sala de aula, diz Bolsonaro. Folha de São Paulo, São Paulo, 25/07/2019. Disponível em: https://www1.folha.uol.com.br/educacao/2019/07/investir-na-educacao-e-exercerautoridade-em-sala-de-aula-diz-bolsonaro.shtml. Acesso em: 28 de agosto de 2019.

RESENDE, Beatriz. Contemporâneos: expressões da literatura no século XXI. Rio de Janeiro: Casa da Palavra: Biblioteca Nacional, 2008.

ZUMTHOR, Paul. Perfomance, recepção e leitura. 1. ed Cosac Naify Portátil. São Paulo: Cosac Naify, 2014.

Recebido em: 02/06/2021

Aceito em: 16/07/2021

\footnotetext{
${ }^{1}$ O Future-se consiste em um plano elaborado pelo Ministério da Educação, o qual propõe para as Universidades Federais obterem recursos do sistema privados. Esse plano recebeu duras críticas da
} 
comunidade acadêmica. Informações disponíveis no site: https://www.politize.com.br/novo-future-se. Acesso em: 25 de maio de 2021. 